\title{
CONTACT PRESSURES IN THE HUMAN HIP JOINT
}

\author{
N. Y. P. AFOKE, P. D. BYERS, W. C. HUTTON
}

From The Polytechnic of Central London

\begin{abstract}
The pressure distribution between the cartilaginous surfaces in the human hip joint was measured using pressure-sensitive film. Five cadaveric hip joints (aged between 58 and 87 years) were measured at three positions and loads, representing three instants in the stance phase of the walking cycle. The pressure distribution was not uniform, indicating that the cartilage did not, to any great extent, distribute the applied load. The maximum pressures recorded were about $10 \mathrm{MN} / \mathrm{m}^{2}$. The anterosuperior surface of the cartilage was identified as an area of high pressure.
\end{abstract}

In previous studies on the mechanics of the human hip joint (Afoke, Byers and Hutton 1980, 1984) it was found that the inter-cartilaginous space was variable in size and location, and that it changed shape with different positions of the joint. It was concluded that this space would be of limited value as a load-distribution mechanism and that cartilage per se should be well able to distribute the applied load. If incongruity had any function, it seemed to be in promoting bulk fluid movement for the purpose of lubrication and nutrition (Afoke, Hutton and Byers 1984).

To obtain a better understanding of the mechanics of the joint, it was thought advantageous to measure the pressure distribution at the cartilage interface during load-bearing. Previous pressure measurements in the hip have been carried out either directly or indirectly. Direct measurements have mostly involved the insertion of piezo-electric transducers in the acetabulum (Christel, Derethe and Sedel 1976; Mizrahi et al. 1981; Adams and Swanson 1985); in these experiments, a limited number of transducers were used and it was difficult to infer the pressure distribution over the whole of the cartilage surface. On the other hand, Rushfeld, Mann and Harris (1979), using an instrumented endoprosthesis, were able to obtain the pressure contours on the cartilage when the hip was loaded. However, the use of a prosthesis has its limitations, mainly because the natural incongruity is

N. Y. P. Afoke, PhD, Research Assistant

W. C. Hutton, DSc, Professor of Biomechanics

The Polytechnic of Central London, Faculty of Engineering and Science, School of Mechanical and Computer Aided Engineering, 115

New Cavendish Street, London WIM 8JS, England.

P. D. Byers, FRCPath

Institute of Orthopaedics, Brockley Hill, Stanmore, Middlesex HA7 4LP, England.

Requests for reprints should be sent to Dr P. D. Byers.

(C) 1987 British Editorial Society of Bone and Joint Surgery $0301-620 \mathrm{X} / 87 / 4127 \$ 2.00$ lost and the cartilage-cartilage interface is replaced by a cartilage-metal interface.

Pressure-sensitive film has recently become available (Fujifilm Prescale [Low Grade]) and we thought it might overcome these limitations. Using this film, we have developed a technique previously used to measure pressure in the lumbar apophyseal joints (Lorenz, Patwardhan and Vanderby 1983; Dunlop, Adams and Hutton 1984). With this technique, we have been able to test the hypothesis that, since the space due to incongruity is effaced at the relatively low load of $1 x$ body weight (BW), it would be of limited value as a loaddistribution mechanism and that cartilage per se is able to distribute the applied load evenly.

\section{MATERIALS AND METHODS}

Hip joints were obtained from routine necropsies and were stored in sealed polythene bags at $-20^{\circ} \mathrm{C}$ until required. Before testing, they were thawed at room temperature and all the excess soft tissue and the labrum were removed. The disarticulated specimen was then mounted by first cutting the ilium and the femoral shaft in such a way that the direction of the applied force simulated that in vivo. The cut ends of the joint components were mounted in cups using quick-setting dental cement. Wood screws were inserted in the cortical bone to improve the fixing of the specimen to the cement. The pressure-sensitive film. The film (Fujifilm Prescale [Low Grade]) is $0.2 \mathrm{~mm}$ thick and consists of two sheets of polyester, one coated with a layer of micro-encapsulated, colour-forming material (A-sheet) and the other with a colour-developing material (C-sheet). The pressure range of the film sandwich is 1 to $10 \mathrm{MN} / \mathrm{m}^{2}$. When the two sheets are pressed together, some of the microcapsules burst and their contents are developed by the material on the other sheet. The density of the red colour produced is a measure of the pressure applied. For 


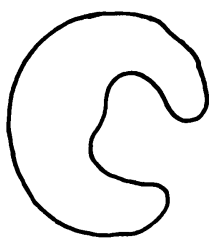

Fig. 1

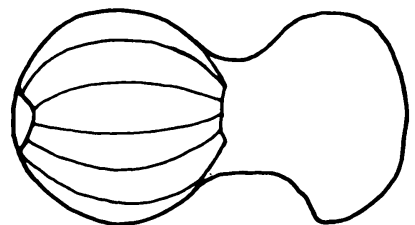

Fig. 2

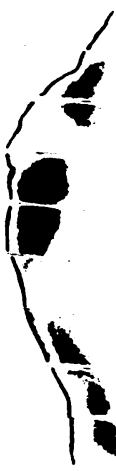

Fig. 3
A typical pressure print taken from a right hip. Figure 1 - The cartilage outline for the acetabulum. Figure 2 - The femoral head with the lanceolate shapes in place. Figure 3 - The lanceolate shapes have been peeled from the femoral head; the shaded areas represent a true view of the pressure print for the acetabulum

instantaneous pressure measurements, the load has to be applied within five seconds and removed within another five seconds. The paper was calibrated by applying known forces to a cylindrical punch to produce a range of pressure from 1 to $10 \mathrm{MN} / \mathrm{m}^{2}$. The colour density was measured with a double-beam, analogue-recording microdensitometer used in the reflection mode. The accuracy of the result is estimated to be better than $\pm 6 \%$.

In the experiments described, the low-grade film was used in every case. However, when the pressure seemed likely to exceed $10 \mathrm{MN} / \mathrm{m}^{2}$, a second test was carried out using the next grade of film with a pressure range of 7 to $25 \mathrm{MN} / \mathrm{m}^{2}$.

Experimental study. Film was used to obtain the pressure imprint at the cartilage interface of five hip joints obtained from autopsies of people aged 58 to 86 years. Specimens were tested on a servo-controlled hydraulic testing machine in three positions and with loads simulating phases of the walking cycle: heel strike at 3.3 BW, flatfoot or neutral at $1.3 \mathrm{BW}$, and just before toeoff at $4 \mathrm{BW}$.

A specimen was first set in the required position (a more detailed description of this technique is described in Afoke et al. 1984). It was then disarticulated and cling film pulled firmly over the femoral head to provide a moisture-free surface for the pressure-sensitive film. The film sandwich was punched into lanceolate shapes that approximated the development of a sphere. Thus shaped, they were used to cover the femoral head and were held in place with Sellotape at each end. The whole was covered with a second layer of cling film to prevent water damage to the pressure film. The specimen was then re-articulated and the load applied within five seconds. After the load had been removed, the rim of the acetabulum, which was later used as a reference line, was inscribed on to the pressure film. The specimen was then disarticulated and the film, containing the pressure imprint, was extracted and mounted on a sheet of paper. The pressure imprints were later analysed using the microdensitometer.

Figure 1 is a view of the acetabulum of the right hip, Figure 2 shows the lanceolate shapes in place on the femoral head and Figure 3 shows the lanceolate shapes after being peeled from the femoral head (the shaded areas represent the pressure print). During loading, the pressure print is recorded on the underside of the upper sheet of pressure film: this means that the pressure print is a true view for the acetabulum but a mirror image for the femoral head.

During the experiments, the cartilage of the acetabulum was kept moist with Ringer's solution; since the femoral head was wrapped with cling film, moisture loss by evaporation was negligible.

In order to assess the degree of incongruity between the components of the hip, a cast was taken at $40 \mathrm{~N}$ for each of the positions tested (the procedure is fully described in Afoke et al. 1980). However, Impregum F (a polyether rubber impression material) was used to make the casts instead of Surgical Simplex (Howmedica) because it is both fast-setting (about five minutes compared with 30 minutes for Simplex) and nonexothermic. The casts were taken after the pressure film was removed.

In between each position tested, the cartilage was left to recover for about 30 minutes by soaking both the acetabulum and the femoral head in Ringer's solution. Effect of the thickness of the pressure-sensitive film on joint geometry. The application of the pressure film to the femoral head enlarges the head. This creates a small gap $(175 \mu \mathrm{m})$ at the apex of the femoral head and the acetabulum (Fig. 4). In preliminary experiments using

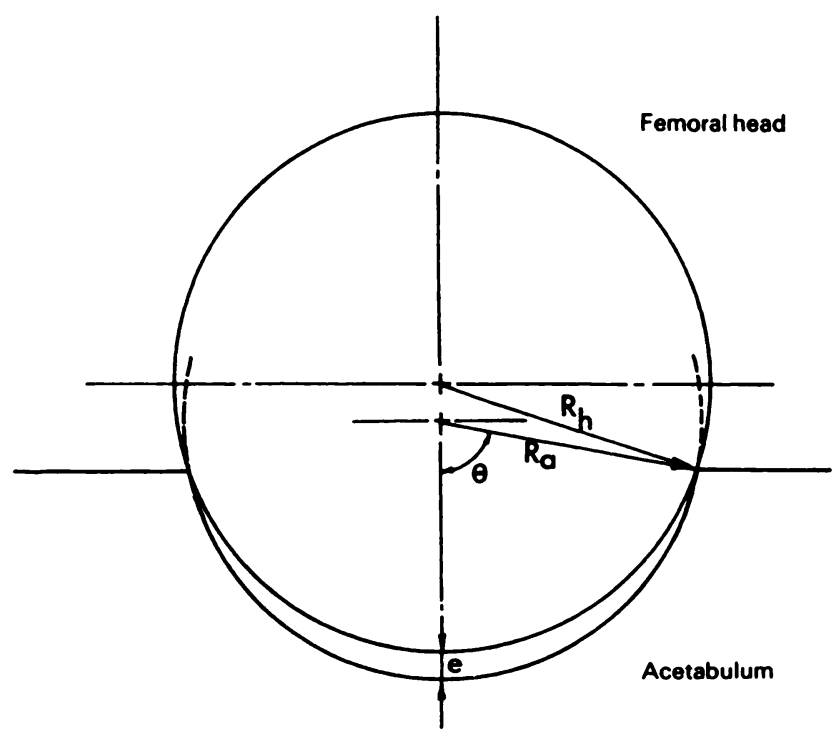

Fig. 4

Figure 4 - Assuming the femoral head $\left(R_{h}\right)$ and acetabulum $\left(R_{a}\right)$ have the same radius $(R)$, covering the femoral head with the pressure film will increase its radius by $0.2 \mathrm{~mm}$ (that is, the thickness of the film). This creates a clearance $(e)$ between the head and the acetabulum. The magnitude of this will depend upon the angle $\theta$ sustained by the acetabular rim in relation to its centre. $R_{h}-R_{a}=0.2 \mathrm{~mm}$ (the thickness of the film). Using Walker's (1969) formula it can be shown that:

$$
\left.\mathbf{R}_{\mathrm{h}}-\mathbf{R}_{\mathrm{a}}=\mathrm{e}\left[\left(1-\mathrm{e} / 2 \mathbf{R}_{\mathrm{a}}\right)\left(1-\cos \theta-\mathrm{e} / \mathbf{R}_{\mathrm{a}}\right)^{-1}-1\right)\right]
$$

Assuming that $R_{\mathrm{a}}=25 \mathrm{~mm}, \theta=60^{\circ}, R_{\mathrm{h}}-\mathrm{R}_{\mathrm{a}}=0.2 \mathrm{~mm}$, thene $=175 \mu \mathrm{m}$ (or very nearly the thickness of the paper). 
Table I. Maximum pressures sustained by cartilage in the five specimens

\begin{tabular}{|c|c|c|c|c|c|c|c|c|}
\hline \multirow[b]{2}{*}{ Specimen } & \multirow[b]{2}{*}{ Age (sex) } & \multirow[b]{2}{*}{$\begin{array}{l}\text { Body } \\
\text { weight } \\
\text { (BW) } \\
\text { (kg) }\end{array}$} & \multicolumn{2}{|c|}{$27^{\circ}$ Flexion } & \multicolumn{2}{|c|}{$0^{\circ}$ Neutral } & \multicolumn{2}{|c|}{$18^{\circ}$ Extension } \\
\hline & & & $\begin{array}{l}\text { Applied } \\
\text { load X } \\
\text { BW }\end{array}$ & $\begin{array}{l}\text { Maximum } \\
\text { pressure } \\
\left(M N / m^{2}\right)\end{array}$ & $\begin{array}{l}\text { Applied } \\
\text { load X } \\
\text { BW }\end{array}$ & $\begin{array}{l}\text { Maximum } \\
\text { pressure } \\
\left(M N / m^{2}\right)\end{array}$ & $\begin{array}{l}\text { Applied } \\
\text { load } x \\
\text { BW }\end{array}$ & $\begin{array}{l}\text { Maximum } \\
\text { pressure } \\
\left(M N / m^{2}\right)\end{array}$ \\
\hline 1 & $76 \mathrm{~F}$ & 60 & 3.3 & 4.9 & 1.3 & 2.9 & 4.1 & 6.0 \\
\hline 2 & $78 \mathrm{M}$ & 65 & 3.3 & 10.2 & 1.3 & 6.2 & 4.1 & 6.5 \\
\hline 3 & $86 \mathrm{~F}$ & 60 & 3.3 & 6.0 & 1.3 & 5.5 & 3.6 & 7.4 \\
\hline 4 & $84 \mathrm{~F}$ & 65 & 3.1 & 10.2 & 1.4 & 6.0 & 4.1 & 8.5 \\
\hline 5 & $58 \mathrm{M}$ & 73 & 3.5 & 10.1 & 2.15 & 8.6 & 4.1 & 10.4 \\
\hline
\end{tabular}

the pressure film, we were able to show that removing this gap (by bringing the two contact surfaces closer together) could be brought about by applying a load of $50 \mathrm{~N}$. This small load is negligible compared to the loads applied in the main experiment and did not affect the pressures recorded.

\section{RESULTS}

The five specimens tested were all normal for their age group in that neither the cartilage of the femoral head nor the acetabulum had any progressive lesions (Byers, Contepomi and Farkas 1970). The maximum pressure recorded at each joint position, with the appropriate applied load, is shown in Table $I$.

Figures 5 to 9 show the pressure prints and the contour maps for each of the five hip joints. Each contour line on the map represents $1 \mathrm{MN} / \mathrm{m}^{2}$; the heavy continuous line delineates the rim of the acetabulum. In some cases there is a space between that line and the start of the print; this was due to loss of cartilage at the acetabular rim (Byers et al. 1970). (Specimen 1 had two lines; the one nearer the pressure print is a marker line and should be ignored.) All the contour maps show that contact between the cartilage surfaces is initiated laterally and, with increasing load, is increased medially towards the fossa. In all the five specimens tested, the maximum contact area occurred in extension. Specimen 5 is somewhat unusual in that the acetabulum had two shallow depressions that carried little load in flexion and in the neutral position; in extension, however, they carried more load.

The contour maps of the five joints show few similarities. We could group Specimens 2 and 4 together since, in flexion, they both had steep pressure gradients in the anterosuperior region, with the pressure rising to a maximum above $10 \mathrm{MN} / \mathrm{m}^{2}$. Specimens 1 and 3 could also be grouped together since they recorded relatively low maximum pressures without steep pressure gradients. Specimen 5 seems to stand alone: the same area of cartilage, near the fossa, made high pressure contact in all three positions (above $10 \mathrm{MN} / \mathrm{m}^{2}$ in flexion and extension, and $8.6 \mathrm{MN} / \mathrm{m}^{2}$ in neutral).
The casts obtained at $40 \mathrm{~N}$ from the five specimens could also be grouped according to their shape and location. Specimens 2, 3 and 4 had an apical space in all the three positions, indicative of a head larger than the acetabulum (Group A as described by Afoke, Byers and Hutton 1984); in Specimen 1 the head was smaller than its acetabulum (Group B2). However, Specimen 5 was different from all the specimens tested previously: two interconnecting shallow depressions were present in the superior acetabular cartilage surface, and the maximum thickness of the cast of those depressions was $8.35 \mathrm{~mm}$.

Comparing the casts with the pressure contour maps revealed that specimens with an apical space (Specimens 2, 3, 4 and 5) had maximal anterosuperior pressure in flexion. Specimen 3 was most incongruous in the neutral position and the load was borne by the anterior and posterior limbs. Specimen 1 is of particular interest in that, although the casts showed that the femoral head was relatively smaller than its acetabulum, the pressure contour map was the most uniform of the five specimens tested.

\section{DISCUSSION}

The loading characteristics of the hip joint have been discussed for many years, and several hypotheses have been produced. Testing of these hypotheses, however, has been impeded by the lack of an easily and reliably performed technique for measuring the load over the whole of the mating articular surfaces. Fujifilm Prescale meets this need and provides quantified values for load at any point. The technique necessitates the introduction into the joint of an artefact, that is, the film, but preliminary tests showed that the effect on the pressure distribution was negligible.

It is difficult to draw any clear comparisons with results from other methods, as reported in the literature. Rushfeld et al. (1979) incorporated transducers into prosthetic femoral heads and reported pressures of up to $6.8 \mathrm{MN} / \mathrm{m}^{2}$; Adams and Swanson (1985) placed transducers under the cartilage of the acetabulum and recorded maximum pressures of $9.57 \mathrm{MN} / \mathrm{m}^{2}$. The load applied in both cases was similar to ours, although the 


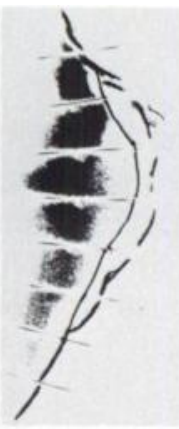

$27^{\circ}$ Flexion

$3.3 \times \mathrm{BW}$

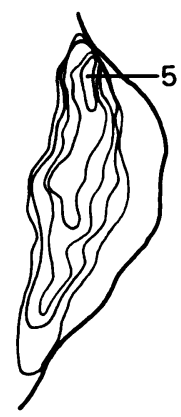

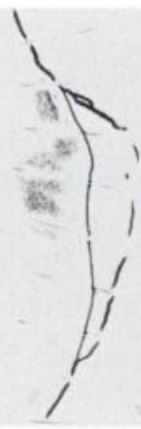

$0 \circ$ Neutral

$1.3 \times B W$

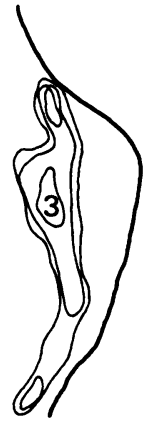

Fig. 5

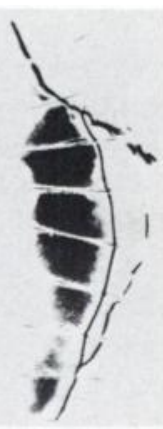

$18^{\circ}$ Extension

$4.1 \times B W$

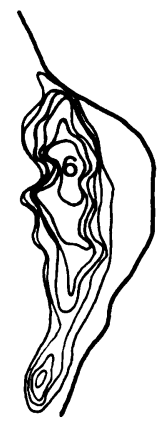

Specimen 1. Left hip of a 76-year-old woman.
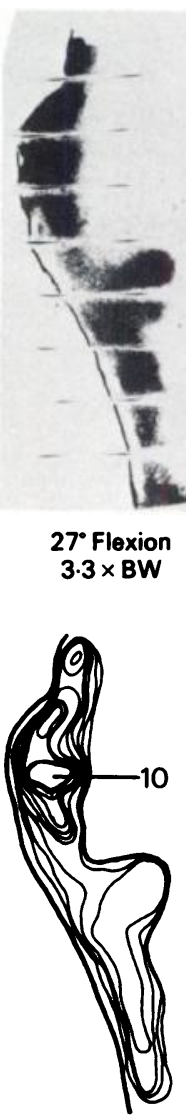

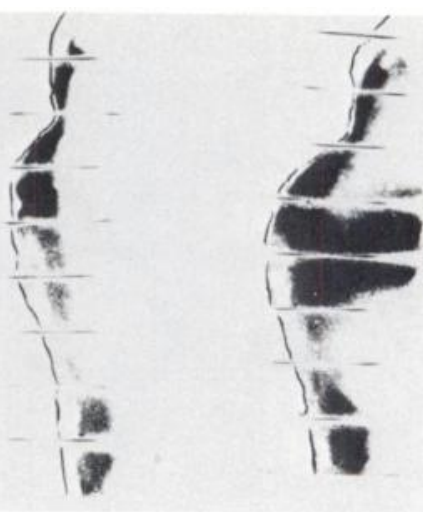

$0^{\circ}$ Neutral
$1.3 \times B W$
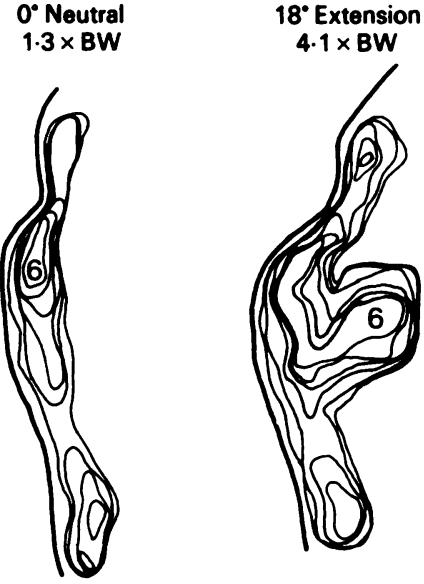

Fig. 6

The results taken from the specimens. Each shows the pressure imprints and contour lines for the three positions tested (drawn at $1 \mathrm{MN} / \mathrm{m}^{2}$ intervals). $B W$, body weight.

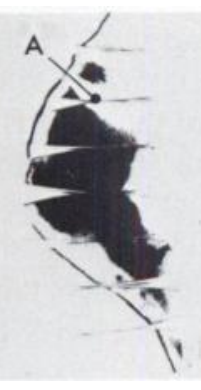

$27^{\circ}$ Flexion $3.3 \times \mathrm{BW}$

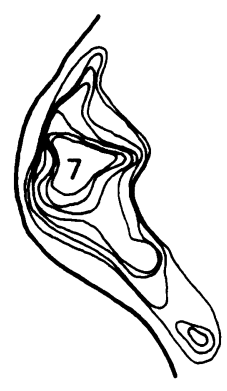

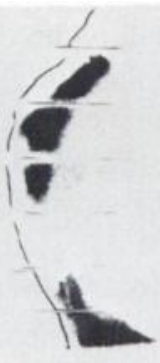

$0^{\circ}$ Neutral
$1.3 \times B W$

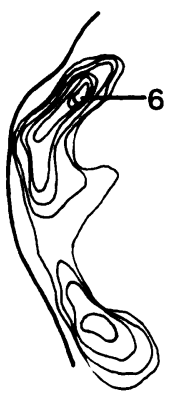

Fig. 7

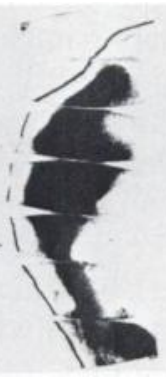

$18^{\circ}$ Extension

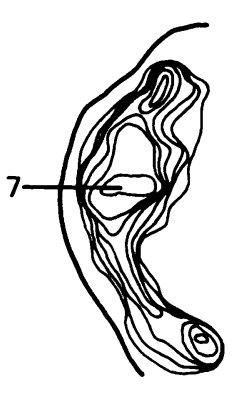

Specimen 3. Right hip of an 86-year-old woman; area $A$ represents a gap due to a groove in the cartilage of the femoral head (cut accidentally at post-mortem).

Specimen 2. Right hip of a 78-year-old man.
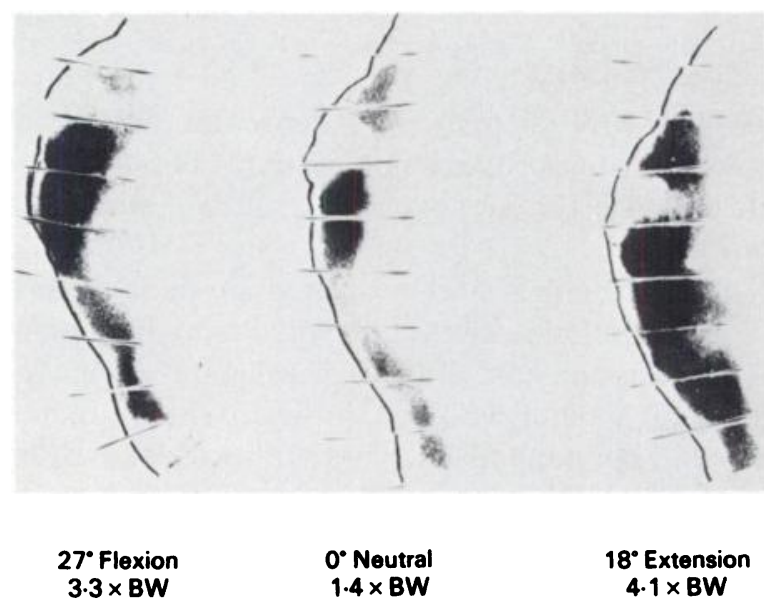
$3.3 \times \mathrm{BW}$
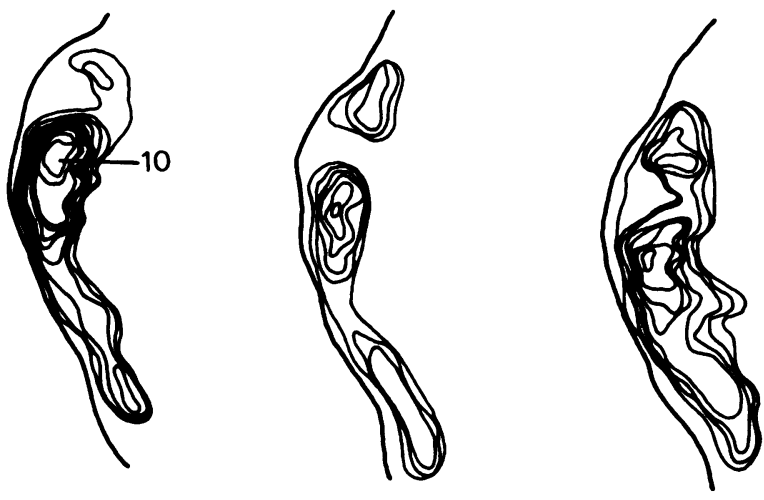

Fig. 8 


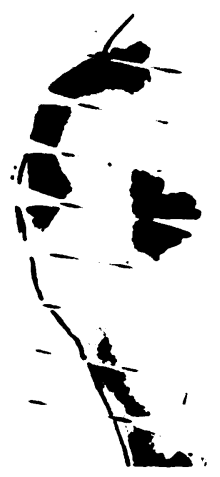

$27^{\circ}$ Flexion $3.5 \times \mathrm{BW}$

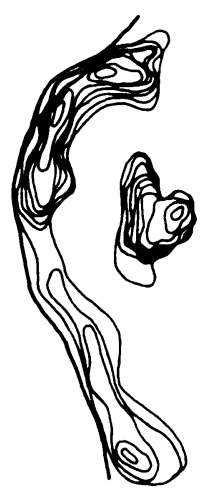

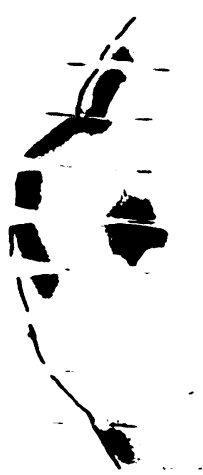

$0 \cdot$ Neutral $2.15 \times \mathrm{BW}$

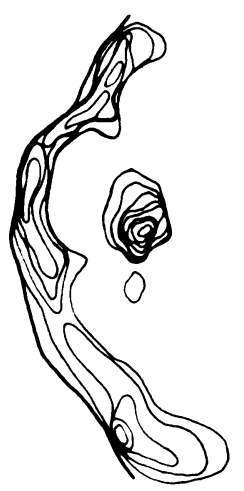

Fig. 9

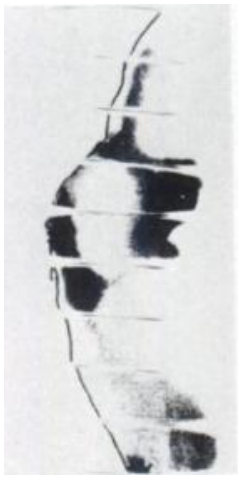

$18^{\circ}$ Extension $4.1 \times B W$

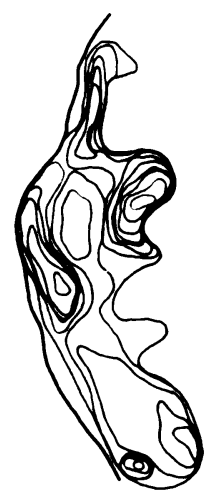

Specimen 5. Right hip of a 58-year-old man.

value of $9.57 \mathrm{MN} / \mathrm{m}^{2}$ found by Adams and Swanson is rather lower than our maximum (perhaps because their sample points might not have been at sites of maximum pressure).

The contact pressures measured in these experiments are the radial stresses perpendicular to the contact surface. The application of load also generates secondary stresses acting parallel to the surface, which are not measured by our method. Analysis studies (Afoke, Byers and Hutton 1982) show that these secondary stresses can be more or less than radial ones, depending on local geometry and stiffness of the cartilage. This combination of stresses should be most interesting where the contour lines are packed close together; the closeness of the lines indicates a steep gradient in radial stress. Pressure differences within the area of steep pressure gradients would set up forces within the cartilage. These forces would produce tensile stresses in the collagen fibres running in the direction of the pressure gradient which, in the case of the hip joint, is lateromedial. Byers et al. (1983) have estimated that the tensile stress induced in the collagen fibre is about 12 times the applied pressure; thus, with a peak pressure of $10 \mathrm{MN} / \mathrm{m}^{2}$, the tensile stress the collagen fibres would have to sustain is $120 \mathrm{MN} / \mathrm{m}^{2}$. As yet we are unable to relate this stress to the ultimate tensile strength of collagen fibres as no data is available. However, it would seem that the structure of cartilage can cope with pressure gradients in the lateromedial direction since the collagen fibres in its superficial layer are predominantly aligned in the lateromedial direction (as shown by the pinprick pattern: Meachim et al. 1974).

Besides providing information on pressure, the pressure prints and contour maps reveal features suggestive of incongruity. If the femoral head and acetabulum were perfectly congruent, or incongruent but symmetrical, then the pressure prints would be uniform and regular in shape. (If a perfectly spherical ball is pressed into a perfectly spherical but slightly larger cup, then the resulting pressure contour lines would be circular.) The shape of the contour maps shown here comes about because of surface irregularities in the mating parts. The question is, which of the two mating parts has the more even surface? It would seem that a spherical femoral head contacting an acetabulum with surface irregularities could produce contour patterns as shown in Specimen 5 (note that the three contour maps have somewhat similar patterns). This similarity could be caused by a spherical femoral head seeing the same irregular surface on the acetabulum at three different positions.

Specimen 2, on the other hand, shows quite different features in flexion and extension; this could indicate surface irregularities on both the head and acetabulum.

Although the tortuous shapes shown by the contour maps may be due to surface irregularities, an alternative explanation might be that, when a spherical head mates with a spherical acetabulum, unusual contour patterns arise through local differences in stiffness of the cartilage or underlying cortical bone. The truth may be a combination of both phenomena.

The central result of our study is that the pressurefilm technique does not corroborate the hypothesis that cartilage distributes the applied load evenly. We have yet to study hips from children and young adults to see if loading patterns change with age. But even at this stage we can identify an area of high pressure, present in the three test positions in all of the specimens, in the anterosuperior segment of the joint. It seems unlikely that this would come about through remodelling of the joint and loss of incongruency (Bullough, Goodfellow and O'Connor 1973). Whatever the reason for this loading pattern, whether developmental or acquired, the site coincides with the most usual location of the progressive cartilage loss seen in osteoarthritis. Even if most joints of the older population show this pattern, with a $3 \%$ prevalence of osteoarthritis of the hip, some additional factor would have to be present : this might be the pressure gradient around the high pressure sites. 


\section{REFERENCES}

Adams D, Swanson SAV. Direct measurement of local pressures in the cadaveric human hip joint during simulated level walking. Ann Rheum Dis 1985;44:658-66.

Afoke NYP, Byers PD, Hutton WC. The incongruous hip joint: a casting study. J Bone Joint Surg [Br] 1980;62-B: 511-4.

Afoke NYP, Byers PD, Hutton WC. A finite element study of the human hip joint. Eng Med 1982;11:17-24.

Afoke NY, Byers PD, Hutton WC. The incongruous hip joint : a loading study. Ann Rheum Dis 1984;43:295-301.

Afoke A, Hutton WC, Byers PD. Synovial fluid circulation in the hip joint. Med Hypotheses 1984;25:81-6.

Bullough P, Goodfellow J, O'Comor J. The relationship between degenerative changes and load-bearing in the human hip. $J$ Bone Joint Surg [Br] 1973;55-B:746-58.

Byers PD, Contepomi CA, Farkas TA. A post mortem study of the hip joint: including the prevalence of the features of the right side. Ann Rheum Dis 1970:29:15-31.

Byers PD, Bayliss MT, Maroudas A, Urban J, Weightman B. Hypothesising about joints. In: Maroudas A, Holborow EJ, eds. Studies in joint disease 2. London: Pitman, 1983:241-76.
Christel P, Derethe P, Sedel L. Mesure par simulation de l'armortissement d'une hanche normale et prothésée. Acta Orthop Belg 1976;42 Suppl 1:183-93.

Dunlop RB, Adams MA, Hutton WC. Disc space narrowing and the lumbar facet joints. J Bone Joint Surg [Br] 1984;66-B:706-10.

Lorenz M, Patwardhan A, Vanderby JR Jr. Load-bearing characteristics of lumbar facets in normal and surgically altered spinal segments. Spine 1983;8:122-30.

Meachim G, Denham D, Emery IH, et al. Collagen alignments and artificial splits at the surface of human articular cartilage. $J$ Anat 1974;118:101-18.

Mixrahi J, Solomon L, Kaufman B, O'Duggan T. An experimental method for investigating load distribution in the cadaveric human hip. J Bone Joint Surg [Br] 1981 ;63-B: 610-3.

Rushfeld PD, Mamn RN, Harris WH. Influence of cartilage geometry on the pressure distribution in the human hip joint. Science 1979;204:413-5.

Walker PS. On the lubrication and wear in human joints. PhD thesis. University of Leeds, 1969. 